\title{
Preliminary Assessment of Body Condition Score as a Possible Marker for the Targeted Selective Treatment of Dairy Sheep Against Gastrointestinal Nematodes
}

\author{
Claudia Tamponi $^{1} \cdot$ Giorgia Dessi $^{1} \cdot$ Antonio Varcasia $^{1}{ }^{10} \cdot$ Stephane Knoll ${ }^{1} \cdot$ Luisa Meloni $^{1} \cdot$ Antonio Scala $^{1}$
}

Received: 23 May 2021 / Accepted: 14 September 2021 / Published online: 6 October 2021

(c) The Author(s) 2021

\begin{abstract}
Purpose In the fight against anthelmintic resistance, targeted selective treatments (TSTs), where only a small percentage of a flock receives treatment, have become increasingly popular. Overall, implementation of such treatments can be based on various parameters including Body condition score (BCS). As infection with non-bloodsucking nematodes, frequently encountered on sheep farms in the central Mediterranean basin, commonly causes bodyweight reduction, the aim of this research is to evaluate the effectiveness of BCS as a parameter for the implementation of TSTs in lactating dairy sheep with subclinical gastrointestinal nematode (GIN) infections from the island of Sardinia, Italy.

Methods Faecal samples from 1012 ewes divided into 2 groups (third and fifth month of lactation) were collected and their BCS recorded. Faecal egg counts and coprocultures were performed for the assessment of the GIN burden and identification of present species.

Results An overall GIN prevalence of $85.4 \%$ with a mean eggs per gram (EPG) of faeces of $210.1 \pm 347.3$ was found. Teladorsagia spp. and Trichostrongylus spp. were the GIN genera most identified. Overall, animals with the lowest BCS had the highest EPG values and a negative correlation $(r=-0.163)$ between the EPG values and BCS of the studied animals was found, which was most significant for older sheep.

Conclusion This research confirmed BCSs and EPG values for GIN in sheep to be negatively correlated, particularly in older ewes. Application of TSTs for lactating sheep with a BCS $<2.25$, especially to older ewes, could be beneficial in case of subclinical GIN infections, although further studies are needed to work out precise recommendation.
\end{abstract}

Keywords Body condition score $\cdot$ EPG $\cdot$ Mediterranean $\cdot$ Sheep $\cdot$ Targeted selective treatment

\section{Introduction}

Gastrointestinal nematodes (GIN) represent a major health and zootechnical concern in small ruminant farming and may have significant negative effects on grazing dairy sheep [1-5].

Anthelmintic interventions are still the most frequently applied control measures against GIN infections [6] and in most cases, implementation of such treatments is done in a somewhat irrational fashion. In fact, anthelmintic treatment is often executed without adequate laboratory diagnostic

Antonio Varcasia

varcasia@uniss.it

1 Parassitologia, Dipartimento di Medicina Veterinaria, Università degli Studi di Sassari, Sassari, Italy support and active substances not always chosen wisely (e.g. based on cost effectiveness, by habit, etc.). Applied drugs are regularly selected without paying attention to the rotation of available molecule groups and/or with errors in posology [7-10]. Consequently, improper use of anthelmintics over the years has led to the onset and subsequent increase of anthelmintic resistance (AR) in GIN, bringing on significant negative repercussions for the control of these parasites, especially in some regions of the world $[5,11,12]$.

The use of targeted selective treatments (TSTs) has become increasingly popular in the fight against AR in GIN and is aimed at reducing the number of animals treated within a flock. More specifically, TSTs entail solely the treatment of the most affected animals (usually a small percentage of the flock) [13, 14], thus leaving most of the animals in the flock untreated, ensuring the presence of larvae in refugia on pastures $[15,16]$. Such larvae play a key role in 
AR prevention as this fraction of the parasite population will compete with resistant parasitic strains within treated animals, limiting their spread $[15,17]$.

Overall, TST programs can be based on various parameters such as: Faecal Egg Counts (FEC), Hematocrit (HCT) values, direct assessments of the degree of anemia through examination of the conjunctival mucosa (ocular mucosa coloration-OMC; FAMACHA method), faecal consistency score, milk production, weight loss and Body condition score (BCS) $[2,13,18-23]$. The choice of parameter varies according to the parasitological situation present (prevalent nematode species), type of production (meat, milk, or wool), available resources and technical circumstances of the farm $[2,24]$. For example, FEC, employed with different threshold values, is an effective parameter but challenging when applied in large flocks [22] since egg excretion is dependent on the physiological situation of treated animals (e.g. after lambing, related to the post-parturient rise) and nematode species present (e.g. Haemonchus contortus females are particularly fecund, leading to high FECs even when worm burdens are low).

Dairy sheep rearing is widespread in particular regions of the Mediterranean basin, such as central-southern Italy and the Italian islands, where Sarda sheep is the most kept breed. More recently, Lacaune sheep and their crosses were introduced in the region as well [25].

Current scientific literature reports the presence of AR in GIN in the Mediterranean, although less severe compared to other sheep rearing regions (France, Spain, UK, Australia, New Zealand) [26]. Regardless, researching and validating new measures in the fight against AR (such as TSTs) is of significant economic-health interest, in particular in geographic areas where infections with bloodsucking nematodes such as $H$. contortus are widespread. Nonetheless, in that specific situation, the application of the FAMACHA method and the evaluation of HCT values may be considered most suitable for worm burden evaluation [22].

BCS is generally considered to be the simplest and cheapest indicator of an animal's fat reserves for the use in periods of high-energy demand, stress and/or sub-optimal nutrition [27] as is for example characteristic of GIN infections [28, 29]. Especially, infections with Trichostrongylus spp., Teladorsagia spp. and other non-bloodsucking nematodes have been known to cause body weight reduction [30].

Previous studies have shown the use of BCS as a parameter for the implementation of TSTs to be very efficient. In this regard, solely sheep with a BCS $\leq 2$ are treated as most animals with BCS $>2$ can endure their GIN burden and thus do not require anthelmintic intervention [31]. Alternatively, some authors believe this treatment threshold should be more dynamic and adapted to the physiological (or productive) situation on a farm, similar to the use of FECs [32]. For instance, Aguirre-Serrano et al. [32] suggested treatment could be administered to sheep with a $\mathrm{BCS}<3$ specifically before mating and calving.

According to Calvete et al. [7], BCS could be used as a parameter for the implementation of TSTs in flocks of meat sheep with subclinical mixed GIN infections and would bring important benefits such as improved productivity and anthelmintic efficacy preservation.

In the lights of this, the aim of this study is to evaluate the effectiveness of BCS as a parameter for the implementation of TSTs in dairy sheep farms in the central Mediterranean basin where subclinical GIN infections with $T$. circumcincta, Trichostrongylus spp. and $H$. contortus are common. Accordingly, authors hope to contribute to AR reduction and help make dairy sheep farming more sustainable and profitable.

\section{Materials and Methods}

\section{Animals and Management}

The current study was conducted in 2019 on an experimental flock of Sardinian $\times$ Lacaune crossbreed milk sheep owned by the Sardinian Research Agency for Agriculture (AGRIS) located in Monastir (Sardinia-Italy, 39 $9^{\circ} 3^{\prime} 04.08^{\prime \prime}$ N $9^{\circ}$ $\left.02^{\prime} 40.18^{\prime \prime} \mathrm{E}\right)$.

All sheep involved were identified through an endoruminal electronic bolus (detected with an automatic reader) and were subjected to the same diet consisting of $4 \mathrm{~h}$ of grazing on Alexandrian clover and Ryegrass meadow-pastures and supplemented with $600 \mathrm{~g}$ of Ryegrass hay and $600 \mathrm{~g}$ of concentrated feed.

Animals within this research were all lactating sheep and were divided into two groups. The first group was comprised of 394 ewes in their third month of lactation (February) and had an average milk production of $1.2 \mathrm{~L} /$ head per day. The second group was comprised of 618 ewes in their fifth month of lactation (April), with an average milk production of 1.1 L/head per day. Animals were subjected to two daily milkings using an automated milking machine. Lambs were separated from their mothers at about 1 month of age.

During the entirety of the research, no signs of clinical mastitis, diarrhea, respiratory symptoms or foot rot were noted within the flock.

\section{Sampling and Laboratory Analysis}

Preliminary direct parasitological analysis was carried out 3 days prior to the main sampling. Post-mortem examination of four regularly slaughtered sheep (inspection of abdominal and thoracic viscera) and coprological examination of five pooled faecal samples composed of five individual samples each was performed. Pooled faecal samples were examined 
through sedimentation and flotation using a Zinc sulphate solution (1.35 specific gravity) and through the Baermann's method.

Within the entire research, faecal samples were collected directly from the rectum during the morning milking. Samples were placed in plastic containers on which the identification number of the animals were reported. Samples were transported in a cool box to the Laboratory of Parasitology and Parasitic Diseases of the Department of Veterinary Medicine of the University of Sassari (Sassari, Sardinia, Italy) for analysis.

Faecal samples collected during main sampling were individually analyzed through the McMaster's technique as described by Raynaud [33] using a supersaturated $\mathrm{NaCl}$ solution (1.2 s.g.) with an analytical sensitivity of $15 \mathrm{eggs} /$ oocysts per grams (EPG/OPG) of faeces to obtain faecal egg count (FEC).

For each group, five pooled faecal samples were created from five individuals testing positive on quantitative analysis (McMaster) each. Following, coprocultures were prepared according to the method described by Euzeby [34]. Coprocultures were stored at $24 \pm 1{ }^{\circ} \mathrm{C}$ for 14 days and cultured third-stage larvae (L3) isolated with a Baermann's apparatus. For each coproculture, at least $100 \mathrm{~L} 3 \mathrm{~s}$ were morphologically identified using morphometric keys described by van Wyk and Mayhew [35].

At the same time of faecal sampling, each animal was subjected to a BCS evaluation. Scoring of all sheep was carried out by the same veterinary researcher and was performed as indicated by Russel et al. [36] and Donoghue et al. [37]. Each animal was given a score ranging from 1 to $5(1=$ emaciated; $5=$ obese $)$ with a precision of 0.25 .

\section{Data Collection and Processing}

All data were collected on a spreadsheet (Microsoft Excel ${ }^{\circledR}$ ) and subsequently processed using Epi Info ${ }^{\mathrm{TM}}$ v. 7.0 (Centers for Disease Control and Prevention [CDC]/World Health Organization [WHO], Atlanta, GA, USA), and Minitab ${ }^{\circledR}$ v. 18.0 (Minitab, Inc., State College, Pennsylvania, USA) software. For the purposes of statistical processing, monitored sheep were divided into four groups according to age; (1) 1.5 years, (2) 2.5 years, (3) 3.5 years and (4) 4.5 years, and in six classes based on FEC; (1) negative, (2) $\leq 100$ EPG, (3) > 100- $\leq 300$ EPG, (4) $>300-\leq 500$ $\mathrm{EPG},(5)>500-\leq 1000 \mathrm{EPG},(6)>1000 \mathrm{EPG}$. EPG data were transformed logarithmically $[\ln (x+1)]$ as it showed a negative binomial distribution (most sheep showed low EPG values). Due to the fact data were not normally distributed (Kolmogorov-Smirnov test: $P<0.01$ ), Spearman's correlation test, Mann-Whitney test and Kruskal-Wallis test were used to compare BCS in sheep stratified by EPG and age classes. Results with $P$ values $<0.05$ were considered statistically significant.

\section{Results}

Preliminary parasitological examination revealed the presence of a single specimen of Cysticercus tenuicollis found in the mesentery, while copromicroscopic evaluation exclusively uncovered GIN eggs and a few Eimeria spp. oocysts.

For the 1012 faecal samples examined within the main analysis, an overall GIN prevalence of $85.4 \%$ (CI 95\% 83.2-87.6) with a mean EPG value of $210.1 \pm 347.3$ was found. A prevalence of $92.1 \%$ (CI 95\% 89.4-94.8) and $81.1 \%$ (CI 95\% 78-84.2, $\chi^{2}=266.82 ; P<0.001$ ), with mean EPG levels equal to $280 \pm 424.9$ and $165.6 \pm 278.5$ (Mann-Whitney test $-W=231,943.5 ; P<0.001)$ were found for both groups, respectively ( 3 and 5 months of lactation).

Coprological analysis showed Nematodirus spp. eggs in $6.9 \%$ (CI 95\% 4.8-9.8) and 4.5\% (CI 95\% 3.2-6.5) of the samples from the third and fifth month of lactation group, respectively. Eimeria spp. oocysts were found in $64.5 \%$ (CI 95 59.7-69.2) of the samples in the first group and in $63.9 \%$ (CI 95 60.1-67.7) in the second. OPG values were low ( $<200$ OPG) in both groups and thus not considered to affect BCS in this study.

Results of the coprocultures carried out for the identification of the GIN species present in both groups showed Teladorsagia circumcincta and Trichostrongylus spp. as the most prevalent nematodes (Table 1).

Average BCS values recorded in February were $2.833 \pm 0.1765$ and $2.822 \pm 0.2661$ in April. No significant difference was found between the BCSs in both groups (Mann-Whitney test; $W=205,547.5 ; P=0.187$ ).

Spearman's correlation between the EPG values of each of the 1012 sheep monitored and their respective BCS was statistically significant $(\mathrm{Rho}=-0.163 ; P=0.000$; $\left.R^{2}=0.0222\right)$. The same correlation stratified according to month of lactation was equal to $\mathrm{Rho}=-0.127$;

Table 1 Species composition of GIN identified by coprocultures

\begin{tabular}{lll}
\hline GIN species & $\begin{array}{l}\text { Third month lacta- } \\
\text { tion group } \\
\% \text { L3 (n. L3) }\end{array}$ & $\begin{array}{l}\text { Fifth month } \\
\text { lactation } \\
\text { group } \\
\% \text { L3 (n. L3) }\end{array}$ \\
\hline $\begin{array}{l}\text { Teladorsagia spp. } \\
\text { Trichostrongylus spp. }\end{array}$ & $49.2 \%(62)$ & $48.7 \%(55)$ \\
$\begin{array}{l}\text { Bunostomum spp. } \\
\text { Haemonchus spp. }\end{array}$ & $7.9 \%(10)$ & $6.6 \%(31)$ \\
$\begin{array}{l}\text { Chabertia } \\
\text { ovina/Oesophagostomum spp. }\end{array}$ & $7.1 \%(9)$ & $8.8 \%(10)$ \\
Cooperia spp. & $5.6 \%(7)$ & $6.2 \%(7)$ \\
\hline
\end{tabular}


Table 2 Correlations between EPG values and BCS scores according to age groups for sheep in their third month of lactation

\begin{tabular}{llccc}
\hline N. sheep & $\begin{array}{l}\text { Age class } \\
\text { (years) }\end{array}$ & $\begin{array}{l}\text { Spearman cor- } \\
\text { relation }\end{array}$ & $P$ & $R^{2 \mathrm{a}}$ \\
\hline 18 & 1.5 & 0.208 & 0.407 & 0.043 \\
$2^{\mathrm{b}}$ & 2.5 & - & - & - \\
174 & 3.5 & -0.095 & 0.231 & 0.009 \\
200 & 4.5 & -0.192 & 0.006 & 0.037 \\
\hline
\end{tabular}

a\% shared variability

${ }^{\mathrm{b}}$ Data not processed due to small number of animals

Table 3 Correlations between EPG values and BCS scores according to age groups for sheep in their fifth month of lactation

\begin{tabular}{lllll}
\hline N. sheep & $\begin{array}{l}\text { Age class } \\
\text { (years) }\end{array}$ & $\begin{array}{l}\text { Spearman cor- } \\
\text { relation }\end{array}$ & $P$ & $R^{2 \mathrm{a}}$ \\
\hline 131 & 1.5 & -0.064 & 0.469 & 0.004 \\
149 & 2.5 & -0.189 & 0.021 & 0.036 \\
176 & 3.5 & -0.165 & 0.028 & 0.027 \\
162 & 4.5 & -0.207 & 0.008 & 0.043 \\
\hline
\end{tabular}

a\% shared variability

Table 4 BCS means stratified according to EPG classes

\begin{tabular}{lllll}
\hline EPG Class & $N$ & Mean & St. dev & $95 \%$ CI \\
\hline 1 & 148 & 2.87 & 0.18 & $(2.83 ; 2.91)$ \\
2 & 378 & 2.83 & 0.18 & $(2.81 . ; 2.86)$ \\
3 & 281 & 2.81 & 0.19 & $(2.79 ; 2.84)$ \\
4 & 91 & 2.82 & 0.50 & $(2.78 ; 2.87)$ \\
5 & 76 & 2.74 & 0.19 & $(2.69 ; 2.80)$ \\
6 & 38 & 2.76 & 0.21 & $(2.69 ; 2.84)$ \\
\hline
\end{tabular}

Pooled st. dev $=0.2336$
$P=0.012$ and $R^{2}=0.0161$ and $\mathrm{Rho}=-0.207 ; P=0.000$ and $R^{2}=0.0428$ in both groups, respectively.

Evaluation of the correlations between EPG and BCS values according to age groups was significant for sheep of 4.5 years of age in the third month of lactation group (Table 2) and for all sheep older than 2.5 years within the fifth month lactation group (Table 3).

Analysis of mean BCS scores stratified according to the respective EPG classes, shown in Table 4, revealed an overall downward trend with the highest BCSs for coprologically negative animals and lowest BCSs for the animals with the highest EPG values (Kruskal-Wallis test: $H$ value $=28.67 ; \mathrm{DF}=5 ; P=0.000)$.

Parallel comparison (Mann-Whitney test) of mean BCSs of sheep stratified by EPG class also showed animals shedding less eggs to have significantly higher BCSs compared to animals with higher EPG values (Table 5). Mean BCSs of sheep within class $2(\leq 100 \mathrm{EPG})$ were significantly higher than those from EPG classes 3 and 4 $(P<0.05)$ and borderline compared to those of EPG class $5(W=80,178.5 ; P=0.053)$ (Table 5).

GIN prevalence rates and mean EPG values in sheep stratified according to BCS are shown in Table 6.

Significant differences in mean EPG values stratified according to BCS were found through Kruskal-Wallis test $(H=27.84 ; \mathrm{DF}=4 ; P=0.000)$.

\section{Discussion}

The present study reports the monitoring of the relationship between FEC and BCSs of dairy sheep with subclinical GIN infections (a situation commonly encountered in flocks in the Mediterranean region) at 3 and 5 months of lactation to better understand the correlation between the two parameters.

Table 5 Parallel comparison of BCS mean scores of sheep stratified by EPG classes (Mann-Whitney test)

\begin{tabular}{|c|c|c|c|c|c|}
\hline & $\begin{array}{l}\text { Mean BCS/EPG } \\
\text { class } 2\end{array}$ & $\begin{array}{l}\text { Mean BCS/EPG } \\
\text { class } 3\end{array}$ & $\begin{array}{l}\text { Mean BCS/EPG } \\
\text { class } 4\end{array}$ & $\begin{array}{l}\text { Mean BCS/EPG } \\
\text { class } 5\end{array}$ & $\begin{array}{l}\text { Mean BCS/EPG } \\
\text { class } 6\end{array}$ \\
\hline $\begin{array}{l}\text { Mean BCS/EPG } \\
\text { Class } 1\end{array}$ & $\begin{array}{l}W=42,362.5 \\
P=0.032\end{array}$ & $\begin{array}{l}W=56,908.0 \\
P=0.004\end{array}$ & $\begin{array}{l}W=9073.0 \\
P=0.000\end{array}$ & $\begin{array}{l}W=6542.0 \\
P=0.000\end{array}$ & $\begin{array}{l}W=2697.0 \\
P=0.002\end{array}$ \\
\hline $\begin{array}{l}\text { Mean BCS/EPG } \\
\text { class } 2\end{array}$ & - & $\begin{array}{l}W=127,466.5 \\
P=0.259\end{array}$ & $\begin{array}{l}W=91,517.0 \\
P=0.021\end{array}$ & $\begin{array}{l}W=89,531.0 \\
P=0.001\end{array}$ & $\begin{array}{l}W=80,178.5 \\
P=0.053\end{array}$ \\
\hline $\begin{array}{l}\text { Mean BCS/EPG } \\
\text { class } 3\end{array}$ & - & - & $\begin{array}{l}W=15,658.0 \\
P=0.141\end{array}$ & $\begin{array}{l}W=52,357.5 \\
P=0.010\end{array}$ & $\begin{array}{l}W=45,695.5 \\
P=0.169\end{array}$ \\
\hline $\begin{array}{l}\text { Mean BCS/EPG } \\
\text { class } 4\end{array}$ & - & - & - & $\begin{array}{l}W=7974.0 \\
P=0.290\end{array}$ & $\begin{array}{l}W=5980.0 \\
P=0.735\end{array}$ \\
\hline $\begin{array}{l}\text { Mean BCS/EPG } \\
\text { class } 5\end{array}$ & - & - & - & - & $\begin{array}{l}W=2265.0 \\
P=0.633\end{array}$ \\
\hline
\end{tabular}


Table 6 Prevalence rates of GIN and EPG mean values stratified according to BCS scores

\begin{tabular}{lllllll}
\hline BCS & Examined & Positives & Prevalence $(\%)$ & EPG mean & St. dev & 95\% CI \\
\hline 2.25 & 12 & 10 & 83.3 & 461.0 & \pm 501.0 & $(266.0 ; 656.0)$ \\
2.50 & 114 & 106 & 93.0 & 289.1 & \pm 451.9 & $(225.8 ; 352.4)$ \\
2.75 & 488 & 429 & 87.9 & 224.0 & \pm 351.2 & $(193.4 ; 254.6)$ \\
3.00 & 364 & 291 & 79.9 & 164.9 & \pm 297.6 & $(129.5 ; 200.3)$ \\
3.25 & 34 & 27 & 79.4 & 140.3 & \pm 209.1 & $(24.4 ; 256.2)$ \\
\hline
\end{tabular}

Pooled st. $\mathrm{dev}=344.464$
Overall, the different degrees of GIN infection detected through FECs in the two investigated lactation groups did not significantly affect their respective BCSs. The average BCS at 3 months after lambing was slightly higher compared to that at 5 months, despite significantly higher EPG values $(280 \pm 424.9$ at three months and $165.6 \pm 278.5$ at 5 months $)$ and a marginally higher milk production.

The higher EPG levels at 3 months postpartum did not affect the animal's BCS in a significant way as, most likely, these would be related to a final stage of the post-parturient rise phenomenon still present at the third month of lactation $[29,38]$ and thus not to represent a quantitative change in the actual number of adult GINs present nor their real pathogenic effect.

In any case, even with subclinical infections mainly caused by Telardorsagia spp. and Trichostrongylus spp. and characterized by an EPG mean of about 200, significant negative correlations between BCS and EPG levels in both lactation groups were found, although with fairly low R2 values (explained variance) $(<2 \%)$. Furthermore, such negative correlations were most evident in sheep from older age classes ( $>3.5$ years) in which the explained variance values (R2) were slightly higher (about 4\%).

In addition, the finding of the non-bloodsucking nematodes Teladorsagia circumcincta and Trichostrongylus spp. as the more prevalent species in the present study, also reported among the prevalent genera in Europe, confirms the applicability of BCS as a parameter for the implementation of TSTs in the area as these worms are recognized to affect weight gain in sheep. A ratio between weight gain in infected and weight gain in control animals of 0.81 and 0.78 , respectively, has been described [4].

Overall, average BCSs showed a significant decrease with increasing EPG classes, serving as further confirmation of the negative correlation between BCS and EPG of GIN in sheep. Regardless, for dairy sheep under the specific conditions within this research, BCS assessment was not found to be a sufficiently precise enough marker for the implementation of TSTs.

Furthermore, it is entirely plausible that the GIN infestation intensity detected within this study does not have any significant influence on the production performance of Sarda $\times$ Lacaune dairy sheep.
On the other hand, $13.3 \%$ of the monitored sheep within this research were classified into EPG classes 5 and 6, i.e. with values $>500$ UPG, and thus should be treated with anthelmintics as indicated by Ambrosi [39].

In conclusion, the results obtained in the present study seem to confirm that, in general, all sheep with BCSs $>2$ to have a GIN burden compatible with production [31], although application of TST for sheep with a BCS $<2.25$, especially the older ewes, could lead to a significant reduction of the GIN egg contamination on pasture.

Although still preliminary, this study showed that in crossbred Sarda $\times$ Lacaune dairy sheep with subclinical GIN infestations at 3 and 5 months postpartum, above all, older sheep would need to be treated as a stronger negative correlation between BCS and EPG was shown for these animals. It would be beneficial to repeat the present study under alternative circumstances in the future, such as in growing animals or dairy sheep under highly parasitic conditions to reach definitive conclusions on the matter.

Funding Open access funding provided by Università degli Studi di Sassari within the CRUI-CARE Agreement.

Open Access This article is licensed under a Creative Commons Attribution 4.0 International License, which permits use, sharing, adaptation, distribution and reproduction in any medium or format, as long as you give appropriate credit to the original author(s) and the source, provide a link to the Creative Commons licence, and indicate if changes were made. The images or other third party material in this article are included in the article's Creative Commons licence, unless indicated otherwise in a credit line to the material. If material is not included in the article's Creative Commons licence and your intended use is not permitted by statutory regulation or exceeds the permitted use, you will need to obtain permission directly from the copyright holder. To view a copy of this licence, visit http://creativecommons.org/licenses/by/4.0/.

\section{References}

1. Cringoli G, Veneziano V, Jackson F, Vercruysse J, Greer AW, Fedele V, Mezzino L, Rinaldi L (2008) Effects of strategic anthelmintic treatments on the milk production of dairy sheep naturally infected by gastrointestinal strongyles. Vet Parasitol 156:340-345. https://doi.org/10.1016/j.vetpar.2008.06.015 
2. Charlier J, Morgan ER, Rinaldi L, van Dijk J, Demeler J, Höglund J, Hertzberg H, Van Ranst B, Hendrickx G, Vercruysse J, Kenyon F (2014) Practices to optimise gastrointestinal nematode control on sheep, goat and cattle farms in Europe using targeted (selective) treatments. Vet Rec 175:250-255. https://doi.org/10.1136/ vr.102512

3. Geurden T, Hoste H, Jacquiet P, Traversa D, Sotiraki S, Frangipane di Regalbono A, Tzanidakis N, Kostopoulou D, Gaillac C, Privat S, Giangaspero A, Zanardello C, Noé L, Vanimisetti B, Bartram D (2014) Anthelmintic resistance and multidrug resistance in sheep gastro-intestinal nematodes in France, Greece and Italy. Vet Parasitol 201:59-66. https://doi.org/10.1016/j.vetpar. 2014.01.016

4. Mavrot F, Hertzberg H, Torgerson P (2015) Effect of gastrointestinal nematode infection on sheep performance: a systematic review and meta-analysis. Parasit Vectors 8:557. https://doi.org/ 10.1186/s13071-015-1164-Z

5. Traversa D, von Samson-Himmelstjerna G (2016) Anthelmintic resistance in sheep gastro-intestinal strongyles in Europe. Small Rumin Res 135:75-80. https://doi.org/10.1016/j.smallrumres. 2015.12.014

6. Torres-Acosta FJ, Hoste H (2008) Alternative or improved methods to limit gastro-intestinal parasitism in grazing sheep and goats. Small Rumin Res 77:159-173. https://doi.org/10.1016/j. smallrumres.2008.03.009

7. Calvete C, González JM, Ferrer LM, Ramos JJ, Lacasta D, Delgado I, Uriarte J (2020) Assessment of targeted selective treatment criteria to control subclinical gastrointestinal nematode infections on sheep farms. Vet Parasitol 277:109018. https://doi.org/10. 1016/j.vetpar.2019.109018

8. Valcárcel F, Meana A, Sacristán E, Uriarte J, Calvete C, Calavia R, Martínez-Valladares M, Rojo-Vázquez F (2013) Small ruminants farm management practices in Spain and its influence on the development of anthelmintic resistance. Parasitol Latinoam 72:151-163

9. Valcárcel F, Aguilar A, Sánchez M (2015) Field evaluation of targeted selective treatments to control subclinical gastrointestinal nematode infections on small ruminant farms. Vet Parasitol 211:71-79. https://doi.org/10.1016/j.vetpar.2015.04.014

10. Rinaldi L, Morgan ER, Bosco A, Coles GC, Cringoli G (2014) The maintenance of anthelmintic efficacy in sheep in a Mediterranean climate. Vet Parasitol 203:139-143. https://doi.org/10. 1016/j.vetpar.2014.02.006

11. Rose H, Rinaldi L, Bosco A, Mavrot F, de Waal T, Skuce P, Charlier J, Torgerson PR, Hertzberg H, Hendrickx G, Vercruysse J, Morgan ER (2015) Widespread anthelmintic resistance in European farmed ruminants: a systematic review. Vet Rec 176:546. https://doi.org/10.1136/vr.102982

12. Herrera-Manzanilla FA, Ojeda-Robertos NF, González-Garduño R, Cámara-Sarmiento R, Torres-Acosta JFJ (2017) Gastrointestinal nematode populations with multiple anthelmintic resistance in sheep farms from the hot humid tropics of Mexico. Vet Parasitol Reg Stud Rep 9:29-33. https://doi.org/10.1016/j.vprsr.2017.04. 007

13. Cringoli G, Rinaldi L, Veneziano V, Mezzino L, Vercruysse J, Jackson F (2009) Evaluation of targeted selective treatments in sheep in Italy: Effects on faecal worm egg count and milk production in four case studies. Vet Parasitol 164:36-43. https://doi.org/ 10.1016/j.vetpar.2009.04.010

14. Gaba S, Cabaret J, Sauvé C, Cortet J, Silvestre A (2010) Experimental and modeling approaches to evaluate different aspects of the efficacy of Targeted Selective Treatment of anthelmintics against sheep parasite nematodes. Vet Parasitol 171:254-262. https://doi.org/10.1016/j.vetpar.2010.03.040

15. Kenyon F, Greer AW, Coles GC, Cringoli G, Papadopoulos E, Cabaret J, Berrag B, Varady M, Van Wyk JA, Thomas E,
Vercruysse J, Jackson F (2009) The role of targeted selective treatments in the development of refugia-based approaches to the control of gastrointestinal nematodes of small ruminants. Vet Parasitol 164:3-11. https://doi.org/10.1016/j.vetpar.2009.04.015

16. Medina-Pérez P, Ojeda-Robertos NF, Reyes-García ME, CámaraSarmiento R, Torres-Acosta JFJ (2015) Evaluation of a targeted selective treatment scheme to control gastrointestinal nematodes of hair sheep under hot humid tropical conditions. Small Rumin Res 127:86-91. https://doi.org/10.1016/2Fj.smallrumres.2015.02. 021

17. van Wyk JA (2001) Refugia-overlooked as perhaps the most important factor concerning the development of anthelmintic resistance. Onderstepoort J Vet Res 68:55-67

18. Bath GF, van Wyk JA (2009) The Five Point Check@ for targeted selective treatment of internal parasites in small ruminants. Small Rumin Res 86:6-13. https://doi.org/10.1016/j.smallrumres.2009. 09.009

19. Cabaret J, Silvestre A, Cortet J, Sauve C (2006) Nematode targeted selective treatments in lambs under temperate climate using weight gains, anaemia or diarrhoea scores. In: ICOPA XI-11 th international congress of parasitology, Glasgow (UK), 6-11 August 2006

20. Sotomaior CS, Rosalinski-Moraes F, Souza FP, Milczewski V, Pasqualin CA (2009) Parasitoses Gastrintestinais dos Ovinos e Caprinos-Alternativas de Controle. Série Informação Técnica, n. 080. Curitiba: Instituto EMATER

21. Cornelius MP, Jacobson C, Besier RB (2014) Body condition score as a selection tool for targeted selective treatment-based nematode control strategies in Merino ewes. Vet Parasitol 206:173-181. https://doi.org/10.1016/j.vetpar.2014.10.031

22. Arece-García J, López-Leyva Y, González-Garduño R, TorresHernández G, Rojo-Rubio R, Marie-Magdeleine C (2016) Effect of selective anthelmintic treatments on health and production parameters in Pelibuey ewes during lactation. Trop Anim Health Prod 48:283-287. https://doi.org/10.1007/s11250-015-0947-8

23. Schwarz K, Bapst B, Holinger M, Thüer S, Schleip I, Werne S (2020) Potentials of using milk performance data and FAMACHA score as indicators for Targeted Selective Treatment in Lacaune dairy sheep in Switzerland. Vet Parasitol X 4:100030. https://doi.org/10.1016/j.vpoa.2020.100030

24. Chylinski C, Cortet J, Neveu C, Cabaret J (2015) Exploring the limitations of pathophysiological indicators used for targeted selective treatment in sheep experimentally infected with Haemonchus contortus. Vet Parasitol 207:85-93. https://doi.org/10. 1016/j.vetpar.2014.10.029

25. Carta A, Casu S, Salaris S (2009) Invited review: current state of genetic improvement in dairy sheep. J Dairy Sci 92:58145833. https://doi.org/10.3168/jds.2009-2479

26. Cringoli G, Veneziano V, Rinaldi L, Sauvé C, Rubino R, Fedele V, Cabaret J (2007) Resistance of trichostrongyles to benzimidazoles in Italy: a first report in a goat farm with multiple and repeated introductions. Parasitol Res 101:577-581. https://doi. org/10.1007/s00436-007-0518-7

27. Kenyon PR, Maloney SK, Blache D (2014) Review of sheep body condition score in relation to production characteristics. N Z J Agric Res 57:38-64. https://doi.org/10.1080/00288233. 2013.857698

28. Kyriazakis I, Anderson DH, Oldham JD, Coop RL, Jackson F (1996) Long-term subclinical infection with Trichostrongylus colubriformis: effects on food intake, diet selection and performance of growing lambs. Vet Parasitol 61:297-313. https://doi. org/10.1016/0304-4017(95)00824-1

29. Coop RL, Kyriazakis I (1999) Nutrition-parasite interaction. Vet Parasitol 84:187-204. https://doi.org/10.1016/s03044017(99)00070-9 
30. Bath GF, Hansen JW, Krecek RC, van Wyk JA, Vatta AF (2001) Sustainable, approaches for managing haemonchosis in sheep and goats. Final Reports of Food and Agriculturae Organization (FAO) Technical Cooperation Project No. TCP/SAF/8821(A), pp 81-89

31. Soto-Barrientos N, Chan-Pérez JI, España-España E, NoveloChi LK, Palma-Ávila I, Ceballos-Mendoza AC, SarabiaHernández JA, Santos-Ricalde RH, Cámara-Sarmiento R, Torres-Acosta JFJ (2018) Comparing body condition score and FAMACHA@ to identify hair-sheep ewes with high faecal egg counts of gastrointestinal nematodes in farms under hot tropical conditions. Small Rumin Res 167:92-99. https://doi.org/10. 1016/j.smallrumres.2018.08.011

32. Aguirre-Serrano AM, Ojeda-Robertos NF, González-Garduño R, Peralta-Torres JA, Luna-Palomera C, Torres-Acosta JFJ (2020) Influence of litter size at birth and weaning on the proportion of Pelibuey ewes treated with an anthelmintic in a targeted selective scheme in the hot humid tropics. Small Rumin 184:106049. https://doi.org/10.1016/j.smallrumres.2020. 106049

33. Raynaud JP (1970) Etude de l'efficacité d'une technique de coproscopie quantitative pour le diagnostic de routine et le controle des infestations parasitaires des bovins, ovins, equines et porcins. Ann Parasitol 45:321-342
34. Euzeby J (1981) Diagnostic Experimental des Helminthoses Animals-Travaux Pratiques d'Helminthologie Veterinaire; Informations Techniques des Services Vétérinaires: Paris, France

35. van Wyk JA, Mayhew E (2013) Morphological identification of parasitic nematode infective larvae of small ruminants and cattle: a practical lab guide. Onderstepoort J Vet Res 80:539. https://doi. org/10.4102/ojvr.v80i1

36. Russel AJF, Doney JM, Gunn RG (1969) Subjective assessment of body fat in live sheep. J Agric Sci 72:451-454

37. Donoghue S, Kronfeld DS (1990) Clinical nutrition of sheep and goats. Vet Clin N Am Food Anim Pract 6:563-576. https://doi. org/10.1016/S0749-0720(15)30832-X

38. Beasley AM, Kahn LP, Windon RG (2012) The influence of reproductive physiology and nutrient supply on the periparturient relaxation of immunity to the gastro-intestinal nematode Trichostrongylus colubriformis in Merino ewes. Vet Parasitol 188:306-324. https://doi.org/10.1016/j.vetpar.2012.03.022

39. Ambrosi M (1995) Parassitologia Zootecnica, EdagricoleEdizioni Agricole, Bologna, pp 159

Publisher's Note Springer Nature remains neutral with regard to jurisdictional claims in published maps and institutional affiliations. 